\title{
LA SENTENCIA DEL TRIBUNAL CONSTITUCIONAL 35/2020, EN EL CASO STRAWBERRY, UN PASO MÁS, AUNQUE NO EL DEFINITIVO, HACIA LA DESAPARICIÓN DEL DELITO DE ENALTECIMIENTO DEL TERRORISMO
}

\author{
The Judgment of the Constitutional Court 35/2020, \\ in the Strawberry case, one more step, although not \\ the final, towards the disappearance of the crime \\ of enlargement of terrorism
}

\author{
ANA VALERO HEREDIA \\ Universidad de Castilla-La Mancha \\ anamaria.valero@uclm.es
}

Cómo citar/Citation

Valero Heredia, A. (2021).

La Sentencia del Tribunal Constitucional 35/2020

en el caso Strawberry, un paso más, aunque no definitivo

hacia la desaparición del delito de enaltecimiento del terrorismo.

Revista Española de Derecho Constitucional, 122, 367-388

doi: https://doi.org/10.18042/cepc/redc.122.11

\section{Resumen}

La configuración legislativa del delito de enaltecimiento del terrorismo del art. 578 del Código Penal y su aplicación judicial parecen contradecir varias doctrinas firmemente acuñadas por el Tribunal Constitucional espańol y por el Tribunal Europeo de Derechos Humanos. Entre ellas se encuentran la doctrina del «efecto desaliento» y la del «riesgo real». El presente es un estudio de dichas doctrinas a partir de la reciente e importante Sentencia del Tribunal Constitucional español 35/2020, en el caso Strawberry. 


\title{
Palabras clave
}

Enaltecimiento del terrorismo; libertad de expresión; incitación a la violencia; efecto desaliento.

\begin{abstract}
The legislative configuration of the crime of glorification of terrorism of article 578 of the Penal Code and of its judicial application, seem to be contrary to several doctrines firmly coined by the Spanish Constitutional Court and by the European Court of Human Rights in many cases. These include the doctrine of chelling effect and that of the real danger. This is a study of said doctrines based on the recent and important Judgment of the Spanish Constitutional Court 35/2020, in the Strawberry case.
\end{abstract}

\section{Keywords}

Glorification of terrorism; freedom of expression; incitement to violence; chilling effect. 
I. INTRODUCCIÓN: LA INCITACIÓN A LA VIOLENCIA TERRORISTA, ÚNICO LÍMITE VÁLIDAMENTE APLICABLE A LA EXPRESIÓN ENALTECEDORA. II. CRITERIOS PARA DETERMINAR CUÁNDO EXISTE INCITACIÓN A LA COMISIÓN DE ACTOS TERRORISTAS. III. EL ARTÍCULO 578 CP Y EL CHILLING EFFECT. IV. CONCLUSIONES: EL ENALTECIMIENTO DEL TERRORISMO, UN VERDADERO «DELITO DE OPINIÓN» CONSTITUCIONALMENTE INADMISIBLE. 5. BIBLIOGRAFIA.

\section{INTRODUCCIÓN: LA INCITACIÓN A LA VIOLENCIA TERRORISTA, ÚNICO LÍMITE VÁLIDAMENTE APLICABLE A LA EXPRESIÓN ENALTECEDORA}

La aparición y consolidación de Internet como canal de comunicación global y el afianzamiento del terrorismo islamista durante la última década han sido los dos factores detonantes de una actuación cada vez más represiva por parte de las democracias occidentales hacia determinados discursos o mensajes nocivos. La capacidad de emitir y recibir opiniones, ideas e informaciones, más o menos veraces en el caso de estas últimas, más o menos aceptadas en el caso de las dos primeras, se ha convertido en un hecho al alcance de todos, siendo la posibilidad de su expansión y divulgación prácticamente incontrolable a nivel práctico (Boix Palop, 2016: 66). Sin embargo, las democracias de corte liberal republicano como la nuestra están tratando de poner vallas al campo con medidas no siempre respetuosas con la libertad de expresión e información, dos de los derechos tradicionalmente definitorios de su propia identidad.

Así, a la reactivación de delitos en desuso o de escasa aplicación práctica como el de ofensas a los sentimientos religiosos, y a la aparición de otros más recientes como los delitos de enaltecimiento y de odio, se les adiciona una mayor represión cuando se llevan a cabo en el marco de Internet. El riesgo de que la divulgación de determinadas ideas «socialmente peligrosas» se potencie masivamente a través de espacios como las redes sociales (principalmente, Facebook y Twitter) ha conducido a una inercia represiva en la que no solo se encuentran los países europeos, sino también Estados Unidos (Post, 1990: 604), país que tradicionalmente ha abanderado la libertad de expresión como 
uno de los derechos de excepcional limitación, aun cuando aquella resulte nociva para la sociedad (Carmi, 2008: 14). El llamado «derecho penal del enemigo» (Cancio Meliá, 2002: 22) parece, pues, el término más adecuado para calificar las distintas técnicas jurídicas adoptadas a uno y otro lado del Atlántico para perseguir determinados discursos como constitutivos de la propia actividad terrorista (Vives Antón, 2001).

En su reciente Sentencia de 25 de febrero de 2020, en lo que podríamos llamar caso Strawberry, el Tribunal Constitucional español vuelve a abordar, por segunda vez, la interpretación constitucional del art. 578 del Código Penal español ${ }^{1}$, que, como es sabido, incluye dos tipos de conductas: el primer

1 Art. 578 CP: «1. El enaltecimiento o la justificación por cualquier medio de expresión pública o difusión de los delitos comprendidos en los artículos 571 a 577 de este Código o de quienes hayan participado en su ejecución, o la realización de actos que entrañen descrédito, menosprecio o humillación de las víctimas de los delitos terroristas o de sus familiares se castigará con la pena de prisión de uno a dos años. El Juez también podrá acordar en la sentencia, durante el período de tiempo que el mismo señale, alguna o algunas de las prohibiciones previstas en el artículo 57 de este Código.

2. Las penas previstas en el apartado anterior se impondrán en su mitad superior cuando los hechos se hubieran llevado a cabo mediante la difusión de servicios o contenidos accesibles al público a través de medios de comunicación, internet, o por medio de servicios de comunicaciones electrónicas o mediante el uso de tecnologías de la información.

3. Cuando los hechos, a la vista de sus circunstancias, resulten idóneos para alterar gravemente la paz pública o crear un grave sentimiento de inseguridad o temor a la sociedad o parte de ella se impondrá la pena en su mitad superior, que podrá elevarse hasta la superior en grado.

4. El juez o tribunal acordará la destrucción, borrado o inutilización de los libros, archivos, documentos, artículos o cualquier otro soporte por medio del que se hubiera cometido el delito. Cuando el delito se hubiera cometido a través de tecnologías de la información y la comunicación se acordará la retirada de los contenidos.

Si los hechos se hubieran cometido a través de servicios o contenidos accesibles a través de internet o de servicios de comunicaciones electrónicas, el juez o tribunal podrá ordenar la retirada de los contenidos o servicios ilícitos. Subsidiariamente, podrá ordenar a los prestadores de servicios de alojamiento que retiren los contenidos ilícitos, a los motores de búsqueda que supriman los enlaces que apunten a ellos y a los proveedores de servicios de comunicaciones electrónicas que impidan el acceso a los contenidos o servicios ilícitos siempre que concurra alguno de los siguientes supuestos:

a) Cuando la medida resulte proporcionada a la gravedad de los hechos y a la relevancia de la información y necesaria para evitar su difusión. 
tipo hace referencia al enaltecimiento o justificación del terrorismo, y el segundo incluye las que conllevan descrédito, menosprecio o humillación de las víctimas, cuya pena se incrementa, desde su reforma del ańo 2015, cuando los hechos se hubieran llevado a cabo mediante la difusión de servicios o contenidos accesibles al público a través de medios de comunicación, Internet, por medio de servicios de comunicaciones electrónicas o mediante el uso de tecnologías de la información.

En esta ocasión, el Tribunal Constitucional resuelve el recurso de amparo interpuesto por el rapero César Strawberry contra la Sentencia del Tribunal Supremo 4/2017, de 18 de enero, que le condenó a un año de prisión por la comisión de un delito de enaltecimiento del terrorismo como consecuencia de la publicación y retuiteo de imágenes y comentarios a través de la red social Twitter. La importancia de esta sentencia, y su especial trascendencia constitucional, no es menor si tenemos en cuenta que la jurisprudencia reciente de los tribunales ordinarios españoles en materia de enaltecimiento del terrorismo ha sido cuando menos inestable (Cabellos Espiérrez, 2018) y, como se verá, contradictoria con la del Tribunal Europeo de Derechos Humanos.

Los tuits publicados por el enjuiciado son los siguientes: «El fascismo sin complejos de Aguirre me hace añorar hasta los GRAPO»; «A Ortega Lara habría que secuestrarle ahora»; «Street Fighter, edición post ETA: Ortega Lara versus Eduardo Madina»; «Franco, Serrano Suñer, Arias Navarro, Fraga, Blas Piñar... si no les das lo que a Carrero Blanco, la longevidad se pone siempre de su lado», "cuántos deberían seguir el vuelo de Carrero Blanco»; "ya casi es el cumpleaños del Rey. ¡Que emoción!», «le voy a regalar un roscón-bomba».

La sentencia de instancia absolutoria - Sentencia de la Sección Primera de la Sala de lo Penal de la Audiencia Nacional 20/2016, de 18 de julio-llevó a cabo una valoración de cada uno de los diferentes tuits hechos públicos por el recurrente partiendo de la base de que para valorar la concurrencia del

b) Cuando se difundan exclusiva o preponderantemente los contenidos a los que se refieren los apartados anteriores.

5. Las medidas previstas en el apartado anterior podrán también ser acordadas por el juez instructor con carácter cautelar durante la instrucción de la causa».

Este artículo se introdujo en el Código Penal por la Ley Orgánica 7/2000, de 22 de diciembre, de modificación de la Ley Orgánica 10/1995, de 23 de noviembre, del Código Penal, y de la Ley Orgánica 5/2000, de 12 de enero, reguladora de la Responsabilidad Penal de los Menores, en relación con los delitos de terrorismo. Capítulo VII del título XXII del libro II redactado por el artículo único de la LO 2/2015, de 30 de marzo, por la que se modifica la LO 10/1995, de 23 de noviembre, del Código Penal, en materia de delitos de terrorismo ( $B O E$ de 31 marzo). 
delito de enaltecimiento y/o de humillación a las víctimas del art. $578 \mathrm{CP}$ «es importante no solo el tenor literal de las palabras pronunciadas, sino también el sentido o la intención con que hayan sido utilizadas, su contexto y las circunstancias concomitantes». Llegando a la conclusión de que los citados tuits no eran constitutivos de ninguna de las dos modalidades del art. $578 \mathrm{CP}$ en la medida en que de ellos no derivaba la intención del acusado de elogiar a la banda terrorista ETA, ni tampoco de humillar o vejar a sus víctimas; que de ellos no se desprendía un llamamiento claro a actuaciones violentas contra aquellas, y que se trataba de expresiones sarcásticas e irónicas que bien podían ser manifestaciones de la libertad artística de su autor.

El Tribunal Supremo, sin embargo, revocó la sentencia de instancia en casación condenando al ahora recurrente al considerar absolutamente irrelevante la intención del autor para la concurrencia del tipo. Así sostuvo expresamente que «la afirmación de que César Montańa no perseguía la defensa de los postulados de una organización terrorista y de que tampoco buscaba despreciar a las víctimas, es absolutamente irrelevante en términos de tipicidad». A lo que añadió que «la estructura típica del delito previsto en el art. 578 CP no precisa la acreditación de con qué finalidad se ejecutan los actos de enaltecimiento o humillación», pues «el mensaje de burla llega a la víctima en su integridad, sin matices aclaratorios de la verdadera intención del autor que los suscribe». Y continuaba: «[...] afirmaciones como las difundidas en la red por César Montaña alimentan el discurso del odio, legitiman el terrorismo como fórmula de solución de los conflictos sociales y, lo que es más importante, obligan a la víctima al recuerdo de la lacerante vivencia de la amenaza, el secuestro o el asesinato de un familiar cercano» (fundamento de derecho 6).

Que la libertad de expresión es un derecho fundamental limitable es una cuestión indiscutible. El sistemático equilibrio de esta con los demás derechos fundamentales y/o bienes constitucionalmente protegidos así lo exige (Urías, 2020: 52). Como es sabido, el primero llamado a buscar dicho equilibrio es el legislador en el desarrollo de los derechos fundamentales y en la concreción de sus límites. Las limitaciones de los derechos fundamentales son aquellas intromisiones restrictivas prima facie de su ámbito de protección que, por este motivo, precisan de justificación conforme al principio de proporcionalidad. A este respecto, cabe anticipar que, en nuestra consideración, la ponderación llevada a cabo por el legislador penal en la redacción del art. 578 del Código Penal español resulta desproporcionada. Veamos por qué.

En primer lugar, cabe recordar que la seguridad pública es un bien constitucionalmente ponderable con la libertad de expresión, así como lo es el derecho al honor de las personas. Previsión que concuerda con lo dispuesto en el art. 10.2 del Convenio Europeo de Derechos Humanos, que prevé la 
posibilidad de restricciones o sanciones en el ámbito de la libertad de expresión siempre que estén previstas por la ley y constituyan medidas necesarias, en una sociedad democrática, para la consecución o protección de una serie de bienes jurídicos entre los que se hallan la seguridad nacional, la seguridad pública o la protección de la reputación de las personas.

El problema radica en que el modo en que el legislador penal español ha tipificado la conducta enaltecedora o justificativa del terrorismo, por un lado, y la de menosprecio y humillación de las víctimas, por otro, constituye, como se verá a lo largo del presente estudio, lo que algunos han llamado un verdadero «delito de opinión» de dudosa constitucionalidad (Correcher Mira, 2019). Y ello porque la indeterminación de conceptos como el de «enaltecer» o «menospreciar» es tal que deja un excesivo arbitrio al juzgador a la hora de concretar la aplicación del delito en el caso concreto. Abriendo la posibilidad de que este entienda constitutivas del tipo la mera adhesión política o ideológica a los objetivos perseguidos por la actividad terrorista o, incluso, como en el presente caso, la burla o la ironía en torno a ella. Un repaso a los pronunciamientos de los últimos años de la Audiencia Nacional y del Tribunal Supremo así lo confirma, pues la disparidad y la contradicción en la interpretación y aplicación de este precepto penal han sido la norma, con las consecuencias negativas que ello conlleva para el principio de seguridad jurídica ${ }^{2}$.

Sin embargo, la doctrina del Tribunal Constitucional hasta la fecha ha salvado la constitucionalidad del precepto. El intérprete supremo de la Constitución se pronunció por primera vez sobre la posible colisión del delito de enaltecimiento del terrorismo con el derecho a la libertad de expresión en su STC 112/2016, de 20 de junio -FF. JJ. 2 a 4-. Y se apoyó en la doctrina acuñada en su anterior Sentencia 235/2007, de 7 de noviembre, sobre la constitucionalidad de los tipos penales referidos a la negación y difusión de ideas que justifiquen el genocidio, para declarar la constitucionalidad del art. $578 \mathrm{CP}$.

2 No es objeto del presente artículo el análisis de la jurisprudencia del Tribunal Supremo y de la Audiencia Nacional en aplicación del art. 578 CP. Baste con referirnos para ejemplificar lo afirmado a las resoluciones de la Audiencia Nacional y del Tribunal Supremo en los casos Strawberry y Cassandra. Mientras que en el primer caso nos encontramos con una sentencia absolutoria por parte de la Audiencia Nacional —SAN 20/2016, de 18 de julio de 2016 - y una sentencia condenatoria por el Tribunal Supremo - STS 4/2017, de 18 de enero-, en el caso Cassandra nos hallamos ante una sentencia condenatoria por la Audiencia Nacional —SAN 9/17, de 29 de marzo de 2017 - y otra absolutoria por el Tribunal Supremo — STS 95/2018, de 4 de febrero-, siendo los hechos de ambos casos prácticamente idénticos. 
Como se recordará, en aquella ocasión sostuvo que la justificación pública de un delito de tal peligrosidad y tan odioso como el genocidio podía ser castigada penalmente sin riesgo a vulnerar la libertad de expresión siempre que tal justificación operase como incitación indirecta a su comisión - FJ 9-, declarando la inconstitucionalidad de la mera negación del genocidio. En la aplicación de esta doctrina al enaltecimiento del terrorismo declaró que «la tipificación de las conductas previstas en el artículo 578 del Código Penal supone una legítima injerencia en el ámbito de la libertad de expresión de sus autores en la medida en que puedan ser consideradas como una manifestación del discurso del odio por propiciar o alentar, aunque sea de manera indirecta, una situación de riesgo para las personas o derechos de terceros o para el propio sistema de libertades». Por ello, continuaba la sentencia, «el legislador puede, dentro de su libertad de configuración, perseguir tales conductas, incluso haciéndolas merecedoras de reproche penal, siempre que no se entienda incluida en ellas la mera adhesión ideológica a posiciones políticas de cualquier tipo, que resultaría plenamente amparada por el art. $16 \mathrm{CE}$ y, en conexión, por el art. $20 \mathrm{CE}$ ( FJ 9).

\section{CRITERIOS PARA DETERMINAR CUÁNDO EXISTE INCITACIÓN A LA COMISIÓN DE ACTOS TERRORISTAS}

En lo que podríamos calificar como una sentencia interpretativa - STC 112/2016, de 20 de junio-, el Tribunal Constitucional pareció condicionar la constitucionalidad del precepto a la correcta determinación de cuándo se produce el aliento o la incitación, aunque sea indirecta, a la comisión de actos terroristas, y a la existencia de un riesgo real para las personas o derechos de terceros o para el propio sistema de libertades. Pero ¿sobre la base de qué criterios cabe entender que ello tiene lugar?

En ausencia de criterios jurisprudenciales sólidos en el ámbito interno, procede acudir a la jurisprudencia del Tribunal Europeo de Derechos Humanos que ha acuñado, a lo largo de los años, una sólida doctrina según la que la determinación de cuándo se produce una verdadera incitación a la comisión de actos terroristas requiere atender: al contexto político/social en que se produce la difusión del mensaje; al medio empleado para su difusión; al impacto social del mensaje; a la intención del emisor y su estatus, y a la idoneidad de la expresión para incitar a la violencia. Veamos algunos casos que lo evidencian (Presno Linera, 2019: 3).

El primero de ellos es el caso Zana c. Turquía, de 25 de noviembre de 1997, en el que el Tribunal europeo estimó conforme al art. 10 del Convenio 
Europeo de Derechos Humanos la detención de un antiguo alcalde que, en el transcurso de una entrevista, manifestó su adhesión al movimiento de liberación nacional del PKK y a sus actuaciones, a pesar de reconocer que este había cometido matanzas de mujeres y niños por error. El TEDH realizó la correspondiente ponderación a través del llamado "test de Estrasburgo", atendiendo al contexto de extrema tensión existente en el sudeste de Turquía en ese momento, al hecho de que se tratase de un cargo político de la mayor ciudad en esa zona, y a que la entrevista había sido publicada en un diario de gran difusión, para llegar a la conclusión de que se trataba de un mensaje lo suficientemente peligroso como para exacerbar el clima ya explosivo de la región, en la que existía una realidad de violencia terrorista. En palabras del Tribunal:

La declaración no puede [...] considerarse aisladamente. Dadas las circunstancias del caso tuvieron una gran repercusión que el demandante no podía ignorar. [...] La entrevista coincidió con atentados mortales perpetrados por el PKK contra civiles en el sudeste de Turquía, lugar donde reinaba, en el momento de los hechos, una tensión extrema. En estas circunstancias, el apoyo al PKK, calificado de «movimiento de liberación nacional», por parte del antiguo alcalde de Diyarbakir, la ciudad más importante del sudeste de Turquia, en una entrevista publicada en un gran periódico nacional, podría agravar una situación ya de por sí explosiva en esa región.

En el caso Sürek c. Turquía, de 8 de julio de 1999, se abordaba la compatibilidad con el art. 10 del Convenio de la condena penal impuesta al director de una revista por publicar dos cartas al director en las que se criticaban duramente las operaciones militares turcas en el sudeste del país. Las cartas acusaban a Turquía de conspirar para la detención, la tortura y el asesinato de los luchadores por la liberación del pueblo kurdo, y afirmaban que cabía tomar por la fuerza los derechos que les son propios. Pues bien, la Corte de Estrasburgo consideró que, por un lado, existía una clara intención de estigmatizar a la otra parte en el conflicto por el uso de términos tales como «ejército fascista turco», «la banda de los asesinos turcos» y «asesinos a sueldo de imperialismo», y, por otro, que las cartas equivalían a una llamada a una venganza sangrienta porque despertaban instintos primarios y reforzaban prejuicios ya arraigados que se habían ido expresando a través de la violencia mortal. Además, atendió al contexto político-social de la zona, el estado de emergencia, para llegar a la conclusión de que «el lector tiene la impresión de que el uso de la violencia es una medida necesaria y justificada de autodefensa contra el agreson.

En el caso Arslan c. Turquía, de 8 de julio 1999, se dirimía el secuestro de un libro en aplicación de la legislación antiterrorista que, bajo el género de 
narrativa histórica literaria, presentaba a los turcos como invasores crueles. Y afirmaba que el pueblo kurdo, a través de su resistencia, había anunciado «la feliz noticia del día en que destruirán la fortaleza de violencia del chovinismo turco». En relación con el contexto social y político de la región, el Tribunal señaló nuevamente la sensible la situación de inseguridad en el sudeste de Turquía, y, por lo que atañe a la intención del autor, afirmó que estaba claro que la contenida en el libro no era una descripción «neutral» de hechos históricos, ya que, a través de su libro, el autor pretendía criticar la acción de las autoridades turcas en el sureste del país y alentar a la población interesada a oponerse.

Sin embargo, el Tribunal mantuvo que el demandante era un mero particular que difundió sus tesis por medio de una obra literaria y no a través de los medios de comunicación, por lo que su impacto potencial en la «seguridad nacional», el «orden» o «integridad territorial» del Estado turco era limitado. Y llegó a la conclusión de que, si bien había en el libro algunos pasajes especialmente duros, que describían un retrato negativo de la población de origen turco, estos no alentaban el uso de violencia, la resistencia armada o el levantamiento.

En el caso Karatas c. Turquía, de 8 de julio 1999, se dirimía la condena del autor de un libro de poemas que, en palabras de la Corte, contenía pasajes muy agresivos con respecto al poder turco. Sin embargo, estimó que la incidencia de una expresión poética — que se dirige, por definición, a un grupo reducido de personas - en la seguridad nacional, en el orden público y en la integridad territorial del Estado era muy limitada. Y es precisamente el argumento de la escasa divulgación y la naturaliza artística del texto lo que determinó, para el Tribunal, su carácter no apologético.

El problema kurdo también está presente en el origen del caso Erdogdu contra Turquía, de 19 de junio de 2000, en el que se dirimía la compatibilidad con el art. 10 del Convenio de la condena al redactor jefe de un periódico que publicó un artículo escrito por uno de los lectores en el que llamaba a los turcos «fascistas» $y$ «fundamentalistas». La Corte afirmó que la publicación cuestionada se produjo en el contexto de la situación en el sudeste de Anatolia y del problema kurdo que había sido objeto de considerable controversia durante años. Por lo tanto, admitió que el artículo no era un mero estudio «neutral» de este problema y afirmó que, a través de él, el autor, aunque fuera indirectamente, estigmatizó tanto la ideología política dominante del Estado como la conducta de las autoridades turcas en esta área. Sin embargo, la Corte consideró que, si bien algunos términos empleados conferían una cierta virulencia a la crítica política del autor, el artículo en sí no podía ser considerado como «una llamada a la venganza sangrienta» ni podía llevar al lector a pensar 
que el uso de la violencia es una medida necesaria y justificada de autodefensa contra el Estado turco.

El caso Ceylan contra Turquía, de 11 de octubre de 2005, es similar al anterior, pues el Tribunal Europeo de Derechos Humanos trataba de la condena de un sindicalista que publicó un artículo en el que acusaba al Estado turco de adoptar medidas represoras contra la clase trabajadora en su conjunto. Y ello en el marco de la legislación antiterrorista prevista para dar respuesta al asunto kurdo, llamado a la movilización de todos los demócratas contra el Estado opresor. El Tribunal de Estrasburgo tuvo en cuenta las circunstancias que rodeaban el caso y, en particular, las dificultades ligadas a la lucha contra el terrorismo, sin embargo, llegó a la conclusión de que, si bien determinados pasajes del artículo litigioso ofrecían una imagen muy negativa del Estado turco y le otorgaban un carácter hostil, sin embargo, no exhortaban al uso de la violencia, ni a la resistencia armada, ni a la sublevación.

Un caso especialmente relevante, por no versar sobre la cuestión kurdoturca y por mostrar muy claramente la doctrina de la Corte de Estrasburgo, es Leroy c. Francia, de 6 de abril de 2009. En él se conocía de la condena impuesta por apología del terrorismo al dibujante del semanario vasco-francés Ekaitza que publicó, dos días después del ataque a las Torres Gemelas de Nueva York en 2001, un dibujo que representaba dicho ataque acompañado de un texto imitativo del eslogan publicitario de la marca Sony: «Todos lo sońábamos... Hamas lo hizo", con la intención, en sus palabras, de representar la destrucción del imperio estadounidense el día del ataque en Nueva York.

En la correspondiente ponderación, la Corte de Estrasburgo prestó especial atención a los términos utilizados para ilustrar el dibujo: que se trataba de una caricatura que puede ser una forma de expresión artística por definición provocativa, por un lado, y que esta se publicó en un contexto político de lucha contra el terrorismo, por otro. Sin embargo, señaló que concurrían unas circunstancias particulares que el autor no debía haber ignorado: el hecho de que la caricatura y el texto que la acompańaba se hubieran publicado el 13 de septiembre, solo dos días después de los atentados, momento en que todo el mundo se hallaba conmocionado por los hechos, sin tomar ninguna precaución lingüística por su parte. Según el Tribunal, esta dimensión temporal era de tal entidad que aumentaba la responsabilidad del dibujante, por lo que su caricatura debía interpretarse como de apoyo a un hecho trágico, desde un punto de vista tanto artístico como periodístico. Además, continuaba la Corte señalando que el impacto de tal mensaje en una región políticamente sensible como la vasca no debía haberse descuidado.

Por otro lado, y en relación con el criterio de la audiencia, señaló que la solidaridad mostrada por los trabajadores de la revista con su compañero y los 
e-mails y cartas de los lectores en su apoyo — publicados en el número siguiente de la revista - evidenciaban que la caricatura generó reacciones que podían incitar a la violencia, a pesar de la escasa difusión del medio. En consecuencia, el Tribunal de Estrasburgo estimó que la obra no criticaba al imperialismo estadounidense, como defendía su autor, sino que apoyaba y glorificaba su destrucción mediante la violencia.

En la misma línea, en el caso Yavuz y Yaylali c. Turquía, de 17 de diciembre de 2013, la Corte de Estrasburgo fue muy explícita al incluir en la incitación a la violencia discursos que no constituyen una apelación directa a esta. El caso trataba de unos manifestantes condenados por hacer propaganda a favor de una organización terrorista —el llamado Ejército Popular de Liberación- Estos habían participado en una manifestación en protesta por la muerte de diecisiete personas en un enfrentamiento con las autoridades turcas. En el evento se leyó un comunicado de prensa en el que los manifestantes acusaron a los funcionarios involucrados en el enfrentamiento de matar a estas personas en violación de la ley y de la mutilación de los cadáveres. Afirmando que el Estado no respetaba el Estado de derecho y que estaba lejos de ser un Estado democrático. Asimismo, se corearon consignas como «Estado asesino tendrá que rendir cuentas», "Los mártires de la revolución son inmortales», «Viva la solidaridad revolucionaria en vivo» $\mathbf{o}$ «Nosotros hemos pagado el precio, nosotros lo vamos a hacer pagar».

La doctrina de la Corte en este caso es especialmente importante, porque afirmó expresamente que ciertas formas de identificación con una organización terrorista y especialmente su glorificación podían considerarse en sí mismas como un apoyo al terrorismo y la incitación a la violencia y al odio. Y sostuvo que la difusión de mensajes de elogio hacia el autor de un atentado, la denigración de las víctimas, o la llamada a financiar organizaciones terroristas podían constituir actos de incitación a violencia terrorista. Pero, en relación con el presente caso, el Tribunal afirmó que la reacción de las demandantes a las muertes mencionadas supuso una crítica de los actos cometidos por las autoridades oficiales, pero no incitó al uso de la violencia, a la resistencia armada o al levantamiento. A la luz del contenido de las consignas críticas enjuiciadas, la Corte llegó a la conclusión de que no constituían propaganda a favor de una organización terrorista, afirmando que las autoridades de un Estado democrático deben tolerar las críticas vertidas sobre los actos cometidos por sus autoridades.

No podemos cerrar este repaso jurisprudencial sin hacer referencia a una recientísima e importantísima sentencia de 28 de agosto de 2018, en el caso Savva Terentyev contra Rusia. Importante porque, por primera vez, la Corte de Estrasburgo empleó expresamente el criterio del riesgo «real e inminente» de 
la jurisprudencia de la Corte Suprema norteamericana. El demandante, un joven bloguero, fue condenado a un año de cárcel por haber incitado al odio a través de comentarios insultantes sobre la actuación de agentes de policía durante un proceso electoral en la provincia de Komi (Rusia), que fueron publicados en un blog. Entre sus comentarios era especialmente hostil el que afirmaba: «Sería genial si en el centro de cada ciudad rusa, en la plaza principal... hubiera un horno, como en Auschwitz, en el que ceremonialmente todos los días, y mejor aún, dos veces al día policías infieles fueran quemados. La gente los estaría quemando. Este sería el primer paso para limpiar a la sociedad de esta inmundicia policial».

En relación con el contexto, es especialmente relevante el siguiente párrafo de la sentencia, en el que, por primera vez, el Tribunal Europeo de Derechos Humanos apeló al criterio del riesgo real e inminente de que se produzca un acto constitutivo de delito o de violencia, que, como se ha señalado, es la piedra angular la doctrina de la Corte Suprema norteamericana sobre la libertad de expresión desde el año 69, el llamado «estándar Brandenburg»:

En el presente caso no hay ninguna indicación en las decisiones de los tribunales nacionales o en las presentaciones del Gobierno de que el comentario del solicitante se haya publicado en un contexto social o político delicado, o que la situación general de seguridad en esa región sea tensa, o que hubo enfrentamientos, disturbios o disturbios contra la policía, o que existía una atmósfera de hostilidad y odio hacia la policía, o cualquier otra circunstancia particular en la que las declaraciones impugnadas podían dar lugar a acciones ilegales inminentes con respecto a la policía y exponerlos a una amenaza real de violencia física.

En relación con las circunstancias concretas del presente caso, la Corte señaló que el pasaje que hablaba sobre la «incineración» de «policías infieles» en hornos como los de Auschwitz era particularmente agresivo y hostil en su tono. Sin embargo, no consideró que pudiera interpretarse en realidad como una llamada para que la gente común «extermine físicamente a los agentes de policía», sino que más bien fue utilizado como una metáfora provocativa, por lo que no podía considerarse una incitación a cualquier acción ilegal, incluida la violencia. Y sostuvo que, aunque la redacción de las declaraciones impugnadas era, de hecho, ofensiva, insultante y virulenta, no podían verse como elementos que despertasen emociones de base o prejuicios incrustados en un intento de incitar al odio o la violencia contra los oficiales de policía rusos; sino que se trataba más bien de la reacción emocional del demandante a lo que vio como una conducta abusiva del personal de la policía. La Corte afirmó que solo en los casos en los que existiese un contexto muy sensible de tensión, 
conflicto armado y lucha contra el terrorismo o disturbios letales cabría estimar que las declaraciones relevantes podían alentar a una violencia capaz de poner a los miembros de las fuerzas de seguridad en riesgo, y que solo en tales casos cabía aceptar la interferencia en la libertad de expresión, algo que no se daba en el presente caso.

Otro elemento importante para la Corte de Estrasburgo es el impacto potencial que tiene el mensaje controvertido en la sociedad. Y en relación con el caso concreto señaló que, en el momento de los hechos, el solicitante no era un blogger conocido o un usuario popular de las redes sociales, y mucho menos una figura pública o influyente. En tales circunstancias, el Tribunal consideró que el potencial del comentario del solicitante para llegar al público y así influir en su opinión era muy limitado.

De esta doctrina que, como hemos visto, ha reiterado la Corte de Estrasburgo en su jurisprudencia desde finales de los años noventa, se ha hecho eco en el ámbito de la Unión Europea la reciente Directiva 2017/541, de 15 de marzo, relativa a la lucha contra el terrorismo, al exigir, en una nueva formulación del delito de "provocación pública a la comisión de un delito de terrorismo", que esta se realice de forma intencionada (Teruel, 2018: 48). Así, su art. 5 dispone:

Los Estados miembros adoptarán las medidas necesarias para garantizar que se tipifique como delito, cuando se cometa intencionadamente, el hecho de difundir o hacer públicos por cualquier otro medio, ya sea en línea o no, mensajes destinados a incitar a la comisión de uno de los delitos enumerados en el artículo 3, apartado 1, letras a) a i), siempre que tal conducta preconice directa o indirectamente, a través, por ejemplo, de la apología de actos terroristas, la comisión de delitos de terrorismo, generando con ello un riesgo de que se puedan cometer uno o varios de dichos delitos.

Y, además, el considerando 10 de la directiva prevé un criterio interpretativo según el cual «en cada caso concreto, al examinar si se ha materializado ese riesgo, se deben tener en cuenta las circunstancias especificas del caso, el autor y el destinatario del mensaje, así como el contexto en el que se haya cometido el acto. También deben considerarse la importancia y la verosimilitud del riesgo al aplicar la disposición sobre provocación pública de acuerdo con el Derecho nacional» (Tapia Ballesteros, 2019).

Pues bien, volviendo al caso Strawberry, cabe señalar que el Tribunal Supremo defendió en su sentencia condenatoria que la intencionalidad del autor de los mensajes era irrelevante para determinar la concurrencia del tipo, afirmando lo siguiente: 
[...] esta Sala no puede identificarse con una interpretación del art. 578 CP que para su aplicación exija la valoración de un dictamen pericial sobre la etiqueta que el autor reivindica para su propia obra artística. Entre otras razones, porque esos complementos explicativos no se incluyen en el mensaje de burla. Este llega a la víctima en su integridad, sin matices aclaratorios de la verdadera intención del autor que los suscribe. La memoria de su propia tragedia no adquiere otra tonalidad cuando el dictamen pericial concluye que ha sido expresado con sátira o que es fruto de la crítica ácida (FJ 16).

Pues bien, parece evidente que una aplicación tal del tipo penal que prescinde de una evaluación de la entidad de los mensajes, de la finalidad con que se emitieron, del contexto en que se insertaban; de la reiteración de estos o del tono en que fueron pronunciados (Cabellos Espiérrez, 2018: 59) resulta incompatible con la doctrina acuñada por el intérprete supremo de la Constitución española en su STC 112/2016, y con la del Tribunal Europeo de Derechos Humanos que acabamos de exponer. Y ello porque, de acuerdo con ambas, se hace necesario huir de interpretaciones literales del art. $578 \mathrm{CP}$ para atender a elementos tales como la incitación al delito, que aun cuando pueda admitirse como «indirecta» debe ser idónea para provocar un riesgo concreto para las personas o derechos de terceros o para el propio sistema de libertades; o, en el caso del descrédito, menosprecio y humillación, una intención clara y directa de humillar (ibid:: 60).

\section{EL ARTÍCULO 578 CP Y EL CHILING EFFECT}

Como es sabido, la valoración en términos de ponderación es un paso previo, inicial y necesario para la realización de juicios posteriores sobre la proporcionalidad de la limitación, que permitan revisar si la armonización de los derechos y bienes constitucionales en conflicto se ha realizado de manera adecuada, es decir, procurando que ninguno de ellos resulte injustificadamente sacrificado. Pues bien, el principal argumento aducido por el recurrente en amparo, el señor César Montaña, más conocido como Strawberry, se refiere a que la sentencia condenatoria del Tribunal Supremo no había ponderado con carácter previo si la conducta enjuiciada suponía el ejercicio del derecho a la libertad de expresión.

En este sentido, el Tribunal Constitucional sostiene en su sentencia objeto del presente análisis que, efectivamente, «procede verificar si las resoluciones judiciales impugnadas, al imponer la sanción penal, han valorado como cuestión previa si la conducta que se enjuicia constituye un ejercicio 
lícito del derecho fundamental a la libertad de expresión y, en ese marco de valoración, han ponderado las diversas circunstancias concurrentes en el caso, pues así lo impone el principio de supremacía de la Constitución y de respeto a los derechos fundamentales» (FJ 4).

Según doctrina reiterada por el Tribunal Constitucional español, cabe la posibilidad de que la conducta enjuiciada constituya ejercicio legítimo de un derecho fundamental, lo que conduciría a la inexistencia del ilícito penal dado que «los hechos probados no pueden ser a un mismo tiempo valorados como actos de ejercicio de un derecho fundamental y como conductas constitutivas de un delito ${ }^{3}$. Pues, aunque la conducta se correspondiese con el tipo penal conforme a su tenor literal, "no resultaría constitucionalmente legítima la imposición de una sanción penal» ${ }^{4}$ porque estaría justificada por obrar el sujeto en ejercicio legítimo de un derecho (Cuerda Arnau, 2007).

En coherencia con ello, el Tribunal Constitucional sostiene en la presente sentencia que el examen realizado por el Tribunal Supremo en su sentencia condenatoria «no resulta suficiente desde la perspectiva del derecho a la libertad de expresión, ya que no pondera con la intensidad exigida por la jurisprudencia constitucional las circunstancias concurrentes en el cason. Ponderación que hubiese permitido "conocer cuáles han sido las bases sobre las que se puede concluir que la conducta del recurrente debía ser considerada como un ejercicio, sea o no extralimitado, del derecho a la libertad de expresión — con la consiguiente entrada en juego del principio de proporcionalidad en la restricción de un derecho fundamental—o debía ser excluida de este concepto» (FJ 5).

Y es que incluso el ejercicio abusivo o extralimitado de un derecho fundamental puede tener cierta relevancia a la hora de analizar un hecho aparentemente delictivo, pues, como señaló el propio Tribunal Constitucional en su Sentencia 136/1999, de 20 de julio, «una reacción penal excesiva frente a este ejercicio ilícito [...] puede producir efectos disuasorios o de desaliento sobre el ejercicio legítimo de los referidos derechos ya que sus titulares, sobre todo si los límites penales están imprecisamente establecidos, pueden no ejercerlos libremente ante el temor de que cualquier extralimitación sea severamente sancionada» (FJ 20). Por tanto, dicha reacción desproporcionada debe ser evitada tanto por «el juez al aplicar la norma penal, como el legislador al definirla» 5 .

Pues bien, la STC Strawberry sostiene que el Tribunal Supremo no llevó a cabo la indispensable valoración de:

\footnotetext{
SSTC 2/2001, de 15 de enero, FJ 2, y 29/2009, de 26 de enero, FJ 3.

STC 104/2011, de 20 de junio, FJ 6.

5 STC 104/2011, de 20 de junio, FJ 6.
} 
[...] la importancia de los mensajes controvertidos desde el punto de vista de la formación de la opinión pública libre y del intercambio de ideas en consonancia con el pluralismo propio de una sociedad democrática; ni una ponderación de si tales mensajes son susceptibles de ser interpretados como manifestaciones de adhesión a opciones políticas legítimas; ni una consideración acerca de si la condena penal de los mensajes podría producir un efecto desaliento o acarrear la desnaturalización del derecho a la libertad de expresión por parte de quienes se propongan ejercitarla mediante la utilización de medios o con contenidos similares; ni un estudio de si el contenido y la finalidad de los mensajes, en su autoría, contexto y circunstancias de quien los emite y de sus destinatarios, es equiparable a la defensa de actitudes violentas contra el orden legal y constitucional (FJ 5).

La doctrina del "efecto desaliento» — deterrent effect- o "efecto escalofriante» — chilling effect - a la que hace referencia el Tribunal Constitucional en el párrafo anterior tiene su origen en la jurisprudencia de Tribunal Supremo norteamericano relativa a la libertad de expresión, concretamente en el caso Gibson v. Florida Legis Investigation Committee, de 25 de marzo de $1963^{6}$. Doctrina que, aplicada a las leyes, proscribe la excesiva vaguedad (vagueness) o amplitud (overbreadth) de sus disposiciones cuando estas producen un efecto de desaliento o disuasorio en la ciudadanía en el legítimo ejercicio de su libertad de expresión por miedo a ser sancionada penalmente. De ello se deduce que las disposiciones penales han de ser concretas y taxativas (Roig Torres, 2020).

Dicha doctrina fue incorporada al acervo constitucional español a partir de la STC 136/1999, de 20 de julio, y constituye un parámetro de control de la proporcionalidad de toda norma que limita un derecho fundamental y, por tanto, de su constitucionalidad (Alcácer Guirao, 2012). No persiguiendo privar a las normas penales de su eficacia intimidatoria sino prohibir que esta se extienda a conductas que son limítrofes con el legítimo ejercicio de la libertad de expresión o que sancione estas con desproporción manifiesta (Cuerda Arnau, 2007).

El efecto desaliento parte de la dimensión institucional u objetiva de los derechos fundamentales. Pues, como afirmó el Tribunal Constitucional en su Sentencia 88/2003, de 19 de mayo:

[...] la dimensión objetiva de los derechos fundamentales, su carácter de elementos esenciales del ordenamiento jurídico, permite afirmar que no basta

6 Gibson v. Florida Legis. Investigation Comm., 372 U. S. 539, $556-57$ (1963). 
con la constatación de que la conducta sancionada sobrepasa las fronteras de la protección constitucional del derecho, sino que ha de garantizarse que la reacción frente a dicha extralimitación no pueda producir por su severidad, un sacrificio innecesario o desproporcionado de la libertad de la que privan, o un efecto disuasor o desalentador del ejercicio de los derechos fundamentales implicados en la conducta sancionada (FJ 8).

Como es sabido, dicha dimensión institucional es especialmente relevante en el caso de la libertad de expresión cuyo ejercicio trasciende al individuo que ejerce el derecho para proyectarse sobre el interés general, dado que su ejercicio contribuye a la formación de una opinión pública libre, «indisolublemente ligada con el pluralismo político, que es un valor fundamental y un requisito del funcionamiento del Estado democrático» ${ }^{7}$. Es esta función institucional lo que explica que comportamientos típicos que no se ajustan plenamente a las "condiciones y límites» del derecho fundamental, pero que «se encuadran en su contenido y finalidad», no deban ser tratados penalmente como cualquier otro acto ilícito. En tales casos, el juez, a la hora de aplicar el tipo penal, debe tomar en cuenta la conexión que mantiene la conducta enjuiciada con el derecho fundamental, pues, de no hacerlo, se corre el riesgo de desalentar el ejercicio legítimo — esto es, ajustado a las condiciones y límitesde ese derecho (Colomer Bea, 2019).

En dicho sentido, la STC Strawberry es modélica, pues afirma:

[...] la posición central que tiene el derecho a la libertad de expresión como regla material de identificación del sistema democrático determina que no solo el resultado del acto comunicativo respecto de los que se puedan sentirse dañados por él, sino también los aspectos institucionales que el acto comunicativo envuelve en relación con la formación de la opinión pública libre y la libre circulación de ideas que garantiza el pluralismo democrático, deben ponderarse necesariamente para trazar el ámbito que debe reservarse al deber de tolerancia ante el ejercicio de los derechos fundamentales y, en consecuencia, los límites de la intervención penal en la materia. La resolución impugnada, al omitir cualquier argumentación sobre este particular, y rechazar expresamente la valoración de los elementos intencionales, circunstanciales y contextuales e incluso pragmático-lingüísticos que presidieron la emisión de los mensajes objeto de la acusación, se desenvuelve ciertamente en el ámbito de la interpretación que corresponde al juez penal sobre el ámbito subjetivo del tipo objeto de la acusación, pero desatiende elementos que, dadas las circunstancias,

$7 \quad$ STC 12/1982, de 31 de marzo, FJ 3. 
resultaban indispensables en la ponderación previa que el juez penal debe desarrollar en materia de protección de la libertad de expresión como derecho fundamental (FJ 5).

En consecuencia, parece posible afirmar con la doctrina que, con carácter general, aquellas medidas que sancionan conductas ilícitas pero que, sin embargo, se encuentran muy próximas a lo que constituye un ejercicio legítimo del derecho son especialmente aptas para desalentar el ejercicio de los derechos fundamentales. Ahora bien, la mera proximidad al ejercicio legítimo de un derecho no constituye una razón suficiente para excluir la aplicación del tipo. Podría decirse que esta proximidad es un indicio, pero que solo a través de la correcta comprensión de las circunstancias que rodean el legítimo ejercicio de un derecho cabe determinar si una medida lo desalienta (De Domingo Pérez, 2003).

Pues bien, en la resolución objeto del recurso de amparo se afirmaba concluyentemente que resultaba irrelevante ponderar cuál era la intención —irónica, provocadora o sarcástica- del recurrente al emitir sus mensajes, en relación con su trayectoria profesional como artista y personaje influyente, con el contexto en que se emitían los mensajes y con el mantenimiento de una línea de coherencia personal de condena de la violencia como medio de solución de conflictos. Ante ello, el Tribunal Constitucional, en coherencia con los criterios exigidos por el Tribunal Europeo de Derechos Humanos que han sido expuestos con anterioridad, sostiene con rotundidad que "aquella intención [...] lejos de constituir una falacia, resulta ser uno de los aspectos indispensables en elanálisis, pues su preterición en tales circunstancias hace definitivamente imposible ponderar si el acto comunicativo debe entenderse como realizado en el ejercicio legítimo de aquel derecho».

Veíamos con anterioridad que en su STC 112/2016, de 20 de junio, el Tribunal Constitucional había afirmado que el art. 578 del Código Penal supone una legítima injerencia en el ámbito de la libertad de expresión de sus autores siempre que no se entienda incluido en el tipo la mera adhesión ideológica a posiciones políticas de cualquier tipo, que resultaría plenamente amparada por el art. $16 \mathrm{CE}$ y, en conexión, por el art. $20 \mathrm{CE}$ (FJ 9). En coherencia con ello, la STC Strawberry sostiene:

[...] el imperativo constitucional de respeto a la libertad de expresión impide categóricamente extraer conclusiones penales de los tuits sin ponderar también el hecho de que los expresados tuits son susceptibles de ser interpretados como producto de la intencionalidad critica en el terreno politico y social a personas que ostentaban la condición de personajes públicos en el momento en que los actos 
comunicativos tuvieron lugar; y que, en uno de los casos, había tomado posición en favor de un determinado partido político.

Llegando a la conclusión de que la sentencia condenatoria no ha dado cumplimiento suficiente a la exigencia de valoración previa acerca de si la conducta enjuiciada era una manifestación del ejercicio del derecho fundamental a la libertad de expresión, al negar la necesidad de valorar, entre otros aspectos, la intención comunicativa del recurrente en relación con la autoría, contexto y circunstancias de los mensajes emitidos. Y, en consecuencia, afirma, «esta omisión, por sí sola, tiene carácter determinante para considerar que concurre la vulneración del derecho a la libertad de expresión del demandante de amparo».

Podemos concluir, por tanto, que el nivel de desaliento que puede afectar al ejercicio legítimo de un derecho fundamental constituye un elemento que, acorde con la dimensión institucional de los derechos fundamentales, debe ser valorado a la hora de determinar la constitucionalidad de un precepto o la admisibilidad de una determinada decisión jurídica (De Domingo Pérez, 2003).

No procede cerrar el presente análisis sin hacer referencia al voto particular del magistrado D. Alfredo Montoya Melgar, que, por un lado, aboga por una utilización preventiva del derecho penal para restringir la libertad de expresión, y, por otro, considera que las opiniones o los mensajes que humillen a las víctimas del terrorismo deben ser excluidos del ámbito de protección de la libertad de expresión por no contribuir a la formación de una opinión pública libre. Sirva todo lo expuesto para evidenciar nuestro claro desacuerdo con su contenido.

\section{CONCLUSIONES: EL ENALTECIMIENTO DEL TERRORISMO, UN VERDADERO «DELITO DE OPINIÓN» CONSTITUCIONALMENTE INADMISIBLE}

En la presente sentencia el Tribunal Constitucional evita pronunciarse sobre la constitucionalidad del art. $578 \mathrm{CP}$, sin embargo, un análisis detallado de sus fundamentos jurídicos conduce a conclusiones similares a la tesis inicial de este trabajo: que la indeterminación del precepto hace difícil trazar una frontera clara entre lo que es mera expresión de juicios de valor o adhesión a una determinada ideología — arts. 20 y 16 CE — y la existencia de un peligro real para bienes jurídicos constitucionalmente protegidos (Ramos Vázquez, 2008). Ello convierte al enaltecimiento del terrorismo, desde nuestro punto de 
vista, en un «delito de opinión» incompatible con el ámbito de protección de la libertad de expresión.

Perseguir en abstracto ideas que resultan incómodas, nocivas o incluso dañinas para la sociedad, identificándolas con la propia actividad terrorista a través del Código Penal, no parece asumible por ordenamientos jurídicos como el nuestro, que otorgan al valor pluralista un carácter primordial. Atrevernos a barrer del debate público lo disidente, en su acepción más amplia, implica asumir un riesgo demasiado grande y, en este caso, real: la desaparición de una opinión pública libre imprescindible para toda sociedad democrática.

\section{BIBLIOGRAFÍA}

Alcácer Guirao, R. (2012). Discurso del odio y discurso político. En defensa de la libertad de expresión de los intolerantes. Revista Electrónica de Ciencia Penal y Criminología, (14), 2. Disponible en: https://bit.ly/3wU7SXM.

Boix Palop, A. (2016). La construcción de los límites a la libertad de expresión en las redes sociales. Revista de Estudios Políticos, 173, 55-112. Disponible en: http://dx.doi. org/10.18042/cepc/rep.173.02.

Cabellos Espiérrez, M. Á. (2018). Opinar, enaltecer, humillar: respuesta penal e interpretación constitucionalmente adecuada en el tiempo de las redes sociales. Revista Española de Derecho Constitucional, 112, 45-86. Disponible en: https://doi.org/10.18042/cepc/ redc.112.02.

Cancio Meliá, M. (2002). "Derecho penal» del enemigo y delitos de terrorismo. Algunas consideraciones sobre la regulación de las infracciones en materia de terrorismo en el Código penal español después de la Ley Orgánica 7/2000. Jueces para la Democracia, 44, 19-26.

Carmi, G. E. (2008). Dignity Versus Liberty: The Two Western Culture of Free Speech. Disponible en: https://doi.org/10.2139/ssrn.1246700.

Colomer Bea, D. (2019). La doctrina del efecto desaliento como punto de conexión entre el Derecho penal y los derechos fundamentales. Cuadernos Electrónicos de Filosofía del Derecho, 41, 97-116. Disponible en: https://doi.org/10.7203/CEFD.41.13969.

Correcher Mira, J. (2019). Límites penales a la libertad de expresión: sobre el enaltecimiento del terrorismo en redes sociales. Cuadernos Electrónicos de Filosofía del Derecho, 39, 322-339. Disponible en: https://bit.ly/2TLGvkq.

Cuerda Arnau, M. L. (2007). Proporcionalidad penal y libertad de expresión: la función dogmática del efecto de desaliento. Revista General de Derecho Penal, (8), 3.

De Domingo Pérez, T. (2003). La argumentación jurídica en el ámbito de los derechos fundamentales. Revista de Estudios Políticos, (122), 141-166.

Presno Linera, M. (2019). La libertad de expresión en la jurisprudencia del Tribunal Europeo de Derechos Humanos y del Tribunal Constitucional español. Cuadernos digitales de 
formación del Consejo General del Poder Judicial-Delitos de expresión en una sociedad democrática, 1-26. Disponible en: https://bit.ly/3dexIOz.

Post, R. C. (1990). The Constitutional Concept of Public Discourse: Outrageous Opinion, Democratic Deliberation, and Hustler Magazine v. Falwell. Harvard Law Review, 103, 601-686. Disponible en: https://doi.org/10.2307/1341344.

Ramos Vázquez, J. A. (2008). Presente y futuro del delito de enaltecimiento y justificación del terrorismo. Anuario da Facultade de Dereito da Universidade da Coruña, 1-23.

Roig Torres, M. (2020). El «discurso del odio» en el sistema norteamericano y europeo. Tratamiento del racismo y la xenofobia en el proyecto de reforma del código penal. Teoría y Derecho, (15), 173-216. Disponible en: https://bit.ly/3y1R55H.

Tapia Ballesteros, P. (2019). Transposición de la directiva 2017/541, de 15 de marzo, relativa a la lucha contra el terrorismo, al ordenamiento espańol: el delito de enaltecimiento del terrorismo. Revista de Estudios Europeos, núm. extraordinario monográfico, (1), 305-321. Disponible en: http://www.ree-uva.es/.

Teruel Lozano, G. (2018) Internet, incitación al terrorismo y libertad de expresión en el marco europeo. InDret.

Urías, J. (2020). De qué diantres hablamos cuando hablamos de libertad de expresión. En I. Spingo, J. A. Estrada Marún y W. Balderas Cardona (coords.). Los derechos fundamentales en el siglo XXI. Vol. XIV. La libertad de expresión en el siglo XXI: Cuestiones actuales y problemáticas (pp. 361-392). Colombia: Academia Interamericana de Derechos Humanos.

Vives Antón, T. S. (2001). Apología del delito, principio de ofensividad y libertad de expresión. En López Guerra (coord.). Estudios de Derecho Constitucional: homenaje al profesor D. Joaquin Garcia Morillo (pp. 279-294). Valencia: Tirant lo Blanch. 